\title{
Characteristics of Strata Behavior during Thick Seam Mining by Fully-Mechanized Top Coal Caving in a Loess-Covered Gullied Region
}

\author{
Xu-feng Wang ${ }^{1,2,3}$, Yang Wang ${ }^{1, *}$, Dong-sheng Zhang ${ }^{1,4}$, Hong-zhi Wang ${ }^{1}$, Yang Zhang ${ }^{1}$, \\ Dongdong Qin ${ }^{1}$ and Chengguo Zhang ${ }^{5}$ \\ 1 School of Mines, China University of Mining \& Technology, Xuzhou 221116, China; \\ wangxufeng@cumt.edu.cn (X.W.); zds@cumt.edu.cn (D.Z.); cumterwhz@cumt.edu.cn (H.W.); \\ zyzy.1025@163.com (Y.Z.); qindongdong@cumt.edu.cn (D.Q.) \\ 2 The Laboratory of Mining-Induced Seismicity Monitoring in Jiangsu Province, China University of Mining \& \\ Technology, Xuzhou 221116, China \\ 3 Key Laboratory of Deep Coal Resource Mining, China University of Mining \& Technology, \\ Xuzhou 221116, China \\ 4 State Key Laboratory of Coal Resources and Safe Mining, China University of Mining \& Technology, \\ Xuzhou 221116, China \\ 5 School of Mining Engineering, University of New South Wales, Sydney, NSW 2052, Australia; \\ chengguo.zhang@unsw.edu.au \\ * Correspondence: wangyang0317@cumt.edu.cn
}

Academic Editor: Saiied Aminossadati

Received: 22 March 2017; Accepted: 19 April 2017; Published: 24 April 2017

\begin{abstract}
This study systematically investigates the overburden movement and strata behavior at a fully-mechanized top coal caving (FMTCC) face in a thick coal seam in a loess-covered gullied region by field measurement and theoretical analysis. A comparative analysis was performed to examine how the attitude of surface gullies and the structure of overburden affect face support resistance. The characteristics and evolution mechanism of strata behavior during FMTCC under gully slopes in a loess-covered gullied region were discovered through a mechanical analysis of the roof structure and a comparison to the mining of a typical shallow seam under gully slopes. The study found that as the FMTCC face advanced, the strata behavior initiated in the middle part of the face and then continued to both ends, and its intensity was higher in the middle part than in the upper and lower parts. During mining under gullies, the increases in support resistance were generally less than $5 \%$ (except for the maximum increases of 7-9\%), indicating that the occurrence of gullies on the surface had little influence on the strata behavior at the FMTCC face. Due to the increased burial depth and the number of key strata, the roof at the FMTCC face under gullies formed a stable load-bearing structure called a voussoir beam, which was the key difference from the strata behavior characteristics in the shallow mine under gullies.
\end{abstract}

Keywords: loess-covered gullied region; thick coal seam; FMTCC face; strata behavior; roof structure

\section{Introduction}

Advancements in mining technology and equipment have made fully-mechanized top coal caving (FMTCC) an important mining technique that can ensure safe and efficient production in mines with suitable conditions [1-5]. Using various methods, scholars have conducted systematic and in-depth research on the overburden movement and strata behavior induced by FMTCC in different conditions. Related research achievements are summarized below. 
Some studies used simulation methods to analyze the patterns of overburden movement during FMTCC under different conditions. Additionally, experimental methods were constantly developed and improved in order to better fit the theoretical research results to field measurements. For example, Wang et al. [6,7] used three-dimensional modeling software to simulate the deformation and failure of surrounding rocks and stress transfer at different roof thicknesses at an FMTCC face with a hard roof. Xie et al. [8,9] revealed the existence of a macro stress shell that was formed of high-stress bunches in the rocks surrounding an FMTCC face through a combination of numerical modeling and analogue modeling. Li et al. [10] simulated an FMTCC process under a river using a physical model and analyzed the influence of barrier pillars on overburden failure at an FMTCC face. Using numerical simulations, Zhu and Peng [11] and Liu et al. [12] discovered the patterns of overburden movement at an FMTCC face with a large mining height and at an FMTCC face in a deep and steeply-dipping seam, respectively.

Furthermore, some researchers applied advanced monitoring methods to field observations of the motion of rock masses at coal faces, and the observation data were accurate enough to effectively explain the patterns of strata behavior and overburden movement. For example, Yun et al. [13] studied the strata behavior due to multi-slicing top coal caving longwall mining along-the-strike direction in steeply dipping extra thick coal seams by the KJ513 dynamic monitoring system. Additionally, Yu [14] adopted EH-4 magnetotelluric and intelligent drillhole optical imager equipment to measure the fracture height of overlying strata in extra-thick coal seams using FMTCC and to investigate the failure mechanism of large-space overlying strata. Using a KDVJ-400 borehole camera, Wang et al. [15] monitored and analyzed the development characteristics of cleavage and fracture in the overburden at an FMTCC face with a large mining height. Chen et al. [16] applied the SOS (Seismological Observation System) microseism monitoring system to monitor the microseismic activities that occurred in the coal and rock mass near the fault area and proposed that weak seismic activity can be used to forecast the danger of rock bursts.

In other studies, theoretical analyses were performed to construct mechanical models, which were then used to investigate the mechanism of strata behavior during FMTCC and to explore methods for determining support resistance. Their results have successfully guided practical mining operations. Alehossein and Poulsen [17] analyzed the deformation and failure mechanism of front top coal and put forward the caving number, which is the multiplication result of the caving factor and yield factor by mechanical analysis and numerical simulation. The results are very useful to assess the potential success of caving in new longwall top coal caving operations and in different mining conditions. Shen et al. [18] built the model of roof structure in fully mechanized top coal caving and found that a dynamic balance arch structure was formed by the roof and surrounding rock in the working face; multi span beam structure was formed in the tendency direction. For instance, a study by He et al. [19] analyzed the relationship of roof fall and rib spalling to support parameters. The effect of support in controlling roof fall and rib spalling was analyzed by setting up a caving arch mechanical model of cataclastic coal and rock mass on fully a mechanized caving face, and the key parameters of support were also determined using numerical simulation. Du and Bai [20] studied the structure of an immediate roof that was in mechanical equilibrium and revealed the formation mechanism and breakage mode of the semi-arch structure formed from the immediate roof of an FMTCC face with a thin-bedrock roof.

Despite plenty of studies in this field, few have considered the influence of surface configuration on the distribution of rock pressure at FMTCC faces. There is evidence from actual mining processes that surface configuration can affect overburden movement and strata behavior. In particular, gullies on the surface have been found to have a marked effect on strata behavior in shallow coal mines. Research has been conducted on the characteristics of overburden movement and strata behavior during the fully-mechanized mining of shallow coal seams under gully slopes. For instance, Wang et al. [21-25] used various methods, such as physical modeling and theoretical analysis, to investigate the movement pattern and failure mechanism of overburden that lay under gully slopes composed of weathered 
bedrock or sandy soil. In their studies, mechanical models were created for stability analysis, and the characteristics of the movement of gully slopes and strata behavior during shallow seam mining were revealed. Furthermore, a method for classifying gully slopes' susceptibility to the influence of shallow seam mining was developed based on the relationship of slope angle and slope height with the intensity of strata behavior. Zhang et al. [26] researched the influence of gullies on the dynamic rock pressure at a coal face under gullied terrain, with a focus on the voussoir beam structure of the main key stratum in the overburden.

Useful results have been obtained from both the theoretical and practical work on the characteristics of overburden failure and strata behavior during the fully-mechanized mining of shallow coal seams under gully slopes. Compared to fully-mechanized mining, FMTCC mining is characterized by a large mining height, a wide scope of overburden movement, and a unique pattern of strata behavior. Most of the existing research on overburden movement and strata behavior during mining under gully slopes has been focused on shallow seams, and, consequently, coal seams buried at depths of 200 to $300 \mathrm{~m}$ under gullies, especially those being mined by FMTCC, have rarely been studied. For this reason, this study analyzed the characteristics of overburden movement and strata behavior during the FMTCC mining of a deep coal seam under gully slopes, using an FMTCC face under gully slopes at the loess-covered Wangjialing coal mine as an example. The characteristics and evolution mechanism of strata behavior at this coal-face were revealed through a mechanical analysis of the roof structure and a comparison with strata behavior observed during the mining of a typical shallow seam under gullies.

\section{Overview}

Situated in the southernmost portion of the Loess Plateau within the western Shanxi Province, the Wangjialing coal mine is largely covered with thick loess. This area has a complex and diverse topography and is crisscrossed by gullies, with the gully slopes ranging from $15^{\circ}$ to $25^{\circ}$. With a relief of $1024.4 \mathrm{~m}$, this area's terrain is characterized by heavily eroded, low to medium high mountains (Figure 1). The No. 20104 coal face is an FMTCC face that is located under a number of V-shaped gullies in this area, and there is a loess layer covering the surface region right above this face, which ranges from 0 to $108.4 \mathrm{~m}$ in thickness. The elevation of this region is between +803 and $+953.98 \mathrm{~m}$. The mining at this face progresses in a direction that is roughly parallel to the trends of the surface gullies. Beneath the loess layer lies the bedrock, which is not exposed on the gully slopes.

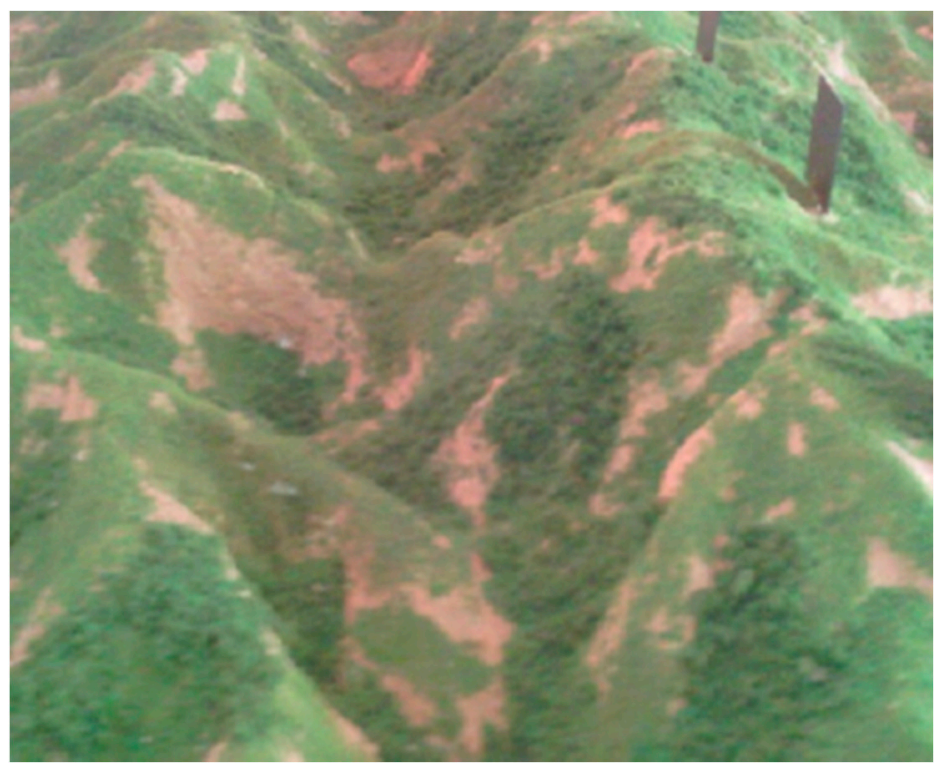

Figure 1. Terrain of the Wangjialing coal mine. 
The main seam of this mine is the \#2 coal seam. This seam has an average burial depth of 292.19 $\mathrm{m}$, an average thickness of $6.84 \mathrm{~m}$, and an average dip angle of $3^{\circ}$. It occurs in stable conditions and has a complex structure. The No. 20104 coal face in the \#2 coal seam measures $230 \mathrm{~m}$ wide and $1214 \mathrm{~m}$ long along its direction of advance. A total of 134 hydraulic supports (rated resistance: $8000 \mathrm{kN}$ ) were set up along this face. Figure 2 shows the layout of the No. 20104 coal face.

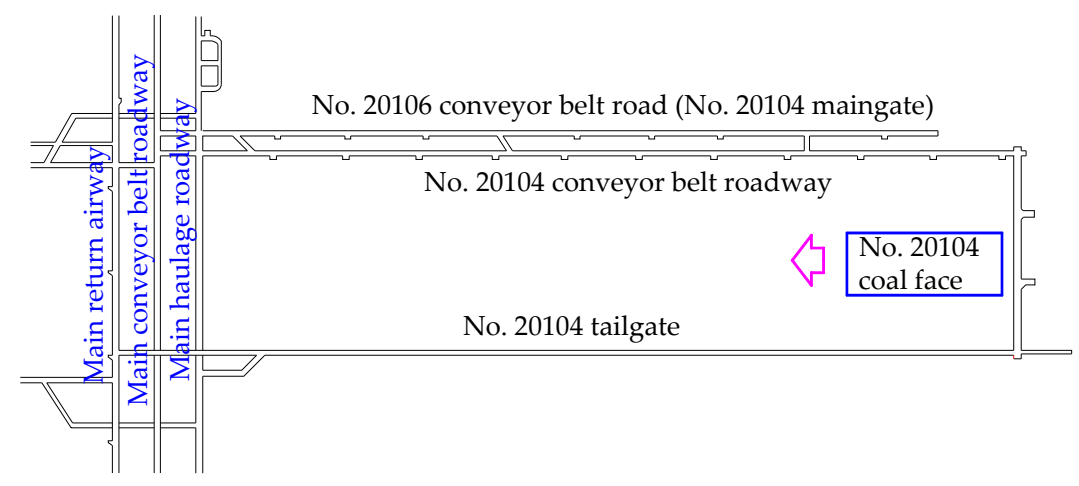

Figure 2. Layout of No. 20104 coal face.

\section{Field Observation of Strata Behavior}

\subsection{Layout of the Observation Station}

An on-line roof monitoring system was used to observe the variation in resistance of the supports located at the No. 20104 coal face. A total of 24 pressure sensors were mounted on the face supports. The first sensor was mounted on support \#1 near the No. 20104 main gate, and the last two sensors were installed on supports \#133 and \#134 near the No. 20104 tailgate, with two adjacent sensors separated by five supports, except for the last two sensors. Figure 3 shows the layout of the strata behavior observation station.

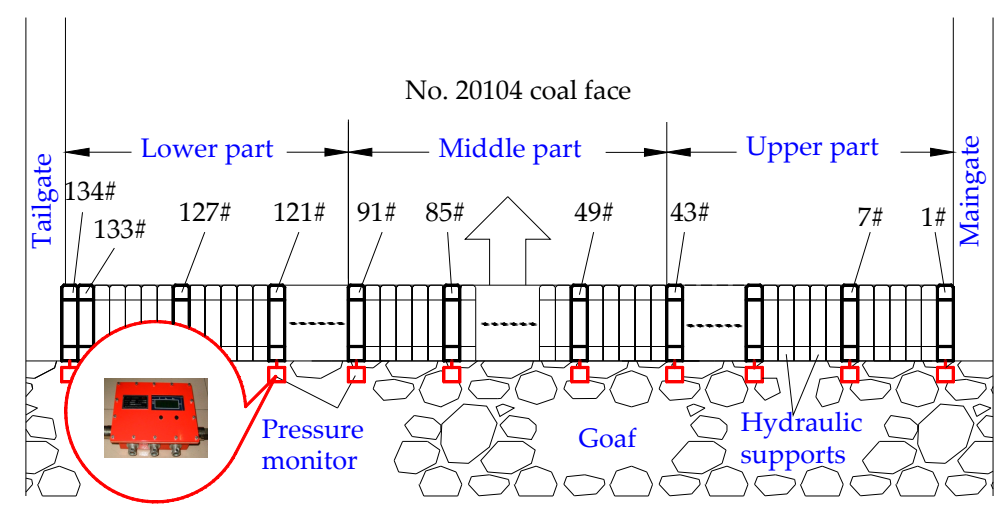

Figure 3. Layout of the strata behavior observation station.

\subsection{Characteristics of Strata Behavior}

The first weighting and the ensuing six periodic weighting events at the No. 20104 coal face were observed. The corresponding characteristics that were recorded are listed in Table 1 , in which $L$ represents the weighting interval, and $T$ is the weighting duration. Figure 4 illustrates the distribution of support resistance at the coal face, with Mmax and Mave denoting the maximum and average support resistance, respectively. 
Table 1. Characteristics of weighting at the coal face.

\begin{tabular}{ccccccc}
\hline \multirow{2}{*}{ Weighting Event } & \multicolumn{2}{c}{ Upper Supports } & \multicolumn{2}{c}{ Middle Supports } & \multicolumn{2}{c}{ Lower Supports } \\
\cline { 2 - 7 } & $\boldsymbol{L} \mathbf{( m )}$ & $\boldsymbol{T} \mathbf{( h )}$ & $\boldsymbol{L} \mathbf{( m )}$ & $\boldsymbol{T} \mathbf{( h )}$ & $\boldsymbol{L} \mathbf{( m )}$ & $\boldsymbol{T} \mathbf{( h )}$ \\
\hline FW & 52.2 & 24 & 48.5 & 26 & 53.8 & 23 \\
PW 1 & 21.3 & 18 & 18.0 & 36 & 22.2 & 10 \\
PW 2 & 24.5 & 24 & 22.1 & 15 & 26.5 & 11 \\
PW 3 & 23.8 & 20 & 22.8 & 21 & 25.3 & 20 \\
PW 4 & 23.5 & 16 & 22.1 & 10 & 24.5 & 8 \\
PW 5 & 24.6 & 10 & 23.6 & 26 & 25.0 & 9 \\
PW 6 & 22.9 & 24 & 20.2 & 12 & 23.4 & 10 \\
\hline
\end{tabular}

Note: FW and PW denote first weighting and periodic weighting, respectively.

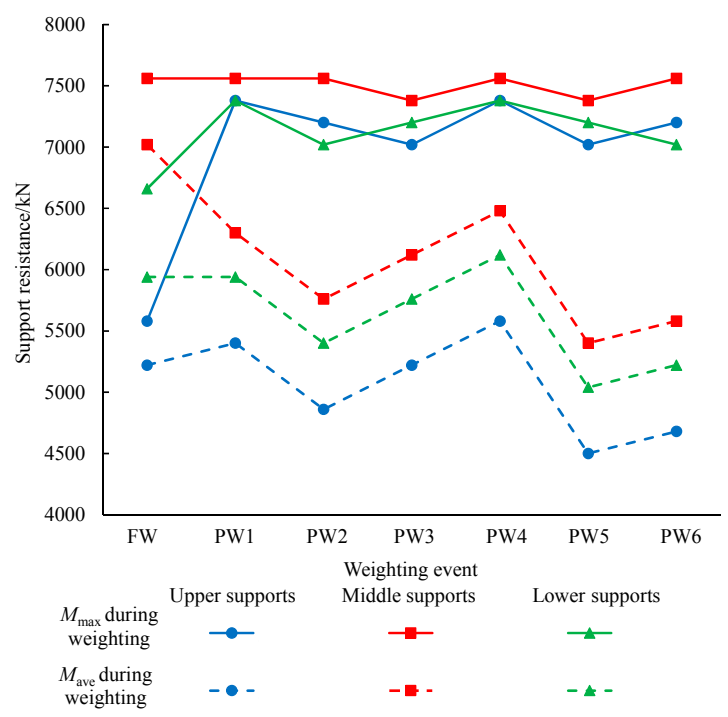

(a)

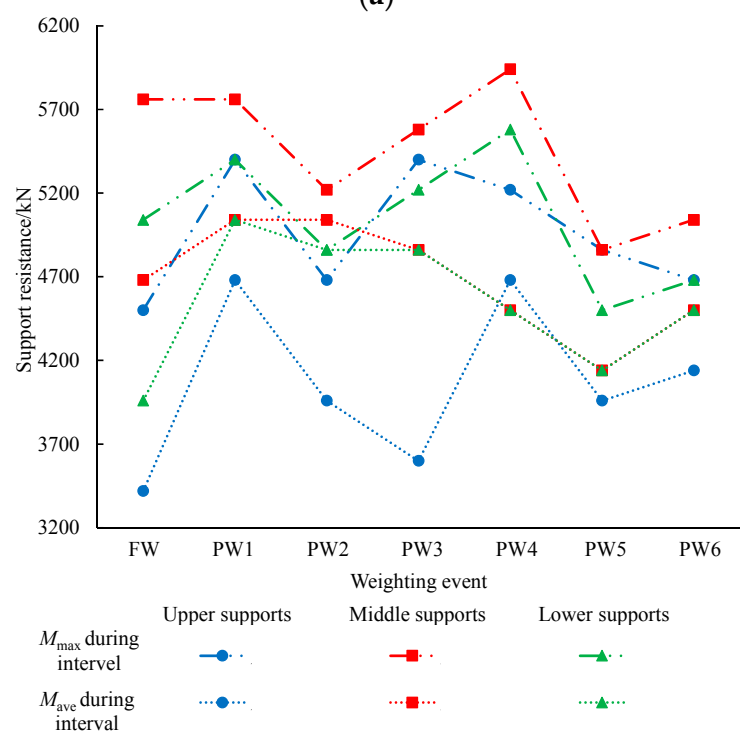

(b)

Figure 4. Statistics on face support resistance. (a) Statistics on face support resistance during weighting; (b) Statistics on face support resistance during interval.

As Table 1 shows, the weighting interval and weighting duration varied between different parts of the coal face. The first weighting interval in the upper, middle, and lower parts of the face were 
$52.5 \mathrm{~m}, 48.5 \mathrm{~m}$, and $53.8 \mathrm{~m}$, respectively, and the corresponding durations were roughly $24 \mathrm{~h}, 26 \mathrm{~h}$, and $23 \mathrm{~h}$, respectively. During the periodic weighting, the average weighting interval in the upper, middle, and lower sections of the face were $23.4 \mathrm{~m}, 21.5 \mathrm{~m}$, and $24.5 \mathrm{~m}$, respectively, and the corresponding average durations were $18.7 \mathrm{~h}, 20.0 \mathrm{~h}$, and $11.3 \mathrm{~h}$, respectively. From the data, it is clear that, compared to the upper and lower parts of the coal face, the middle part had shorter weighting intervals and longer weighting durations, especially during the periodic weighting.

Figure 4 demonstrates that the support resistance increased as weighting occurred. During the intervals between the weighting events, the support resistance did not vary significantly between the support locations and had a relatively flat and "homogenous" distribution. During weighting, the supports along the upper and lower parts of the coal face experienced slight variations in support resistance, with 500 to $1000 \mathrm{kN}$ increases in the average support resistance. In contrast, the supports along the middle section of the face underwent significant increases in support resistance, with increases of 1200 to $2100 \mathrm{kN}$ in the average values and the maximum value peaking at $94.5 \%$ of the rated resistance. It follows that the support resistance was higher in the middle part of the coal face than in its lower and upper parts.

\section{Characteristics of Support Resistance Variation during Mining under a Gully}

A previous study of a shallow mine under gully slopes found that the slope angle $(\alpha)$, slope height $\left(h_{0}\right)$, and burial depth of a coal seam $(H)$ are the key factors affecting support resistance during actual mining and that either an increase in $\alpha$ or $h_{0}$ or a decrease in $H$ can intensify changes in support resistance. Furthermore, the same study introduced the cutting coefficient of a gully $k\left(k=h_{0} / H\right)$ as a criterion for assessing the degree of a gully's influence on support resistance and offered a method for classifying the susceptibility of gullies to the influence of mining operations. Because the thick coal seam analyzed in the current study occurs at depths of 200 to $300 \mathrm{~m}$, the characteristics of strata behavior in the current study should not follow the pattern discovered in the previous study. Nonetheless, it is feasible to use the methods presented in that study and its results as a basis to analyze the strata behavior in this deep mine. By doing so, the current study can identify the surface gullies' influence on face supports during FMTCC of the thick coal seam in the loess-covered gullied region as well as the characteristics of strata behavior at the FMTCC face in the conditions of the Wangjialing coal mine.

As the No. 20104 coal face advanced, the configuration of the surface above it constantly changed along both the strike and dip direction of the face. Comparative analyses of several typical gullies on the surface were performed in order to reveal the influence of gully slopes on strata behavior while the thick coal seam in this loess-covered gullied region was being mined. Seven vertical sections were selected for these gullies, three along the strike of the coal face, and the other four parallel to its dip direction. Support resistance values were recorded during mining and then compared to analyze how the altitudes of the gully slopes within the sections affected support resistance as well as the pattern of strata behavior below the gullies. Figure 5 shows the configuration of the surface of the No. 20104 coal face and the locations of the selected sections.

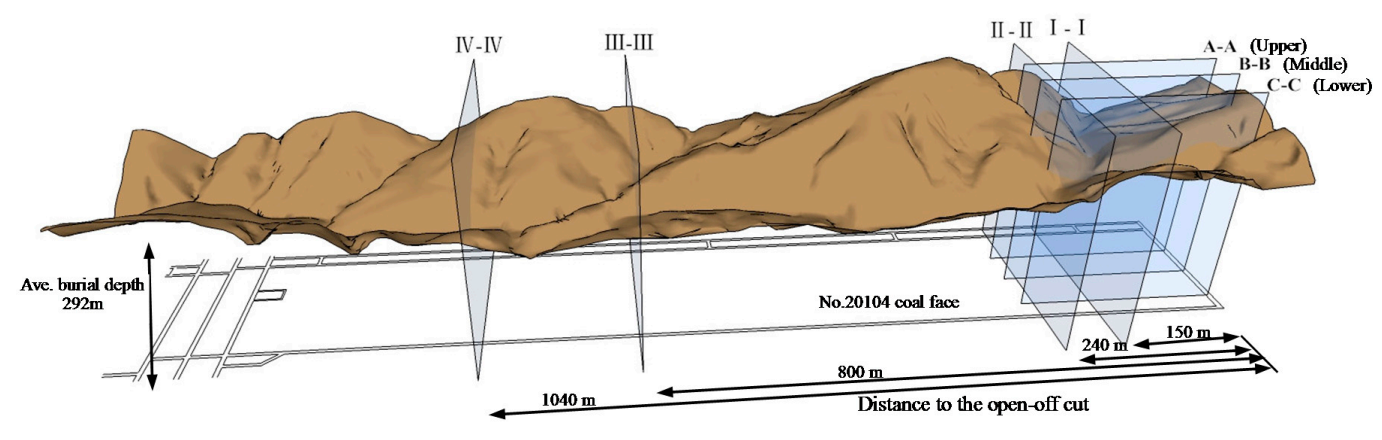

Figure 5. Schematic of surface configuration of No. 20104 coal face and the locations of the sections. 


\section{Distribution of Support Resistance along the Strike of the Coal Face}

Three typical surface gullies were selected over the coal face's upper, middle, and lower parts; the vertical sections passing through these gullies were designated section A-A (supports \#19, \#25, and \#31), section B-B (supports \#61, \#67, and \#73), and section C-C (supports \#103, \#109, and \#115), as shown in Figure 6. When the coal face advanced $80 \mathrm{~m}$ from the open-off cut (point $\mathrm{C}$ ), the surface gully cut through by section $\mathrm{C}-\mathrm{C}$ was in the surface region covering the lower part (Figure $6 \mathrm{c}$ ). As it reached $160 \mathrm{~m}$ in front of the open-off cut (point B), the surface gully cut through by section B-B was over the middle part (Figure 6b). Finally, after an advance of $200 \mathrm{~m}$ (point A), the coal face's upper segment reached under the gully corresponding to section A-A (Figure 6a). The support resistance values at the three points were recorded and analyzed. Figure 7 shows the average support resistance of the upper, middle, and lower supports. Table 2 compares the parameters of the gully slopes within the three sections and the corresponding support resistances. In this table, $R_{\max }$ represents the maximum support resistance, and $K_{R}$ is the ratio of maximum support resistance to average support resistance.

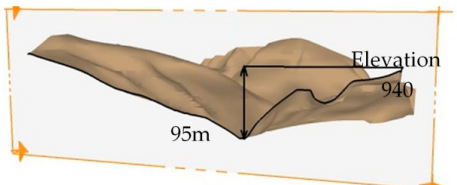

(a)

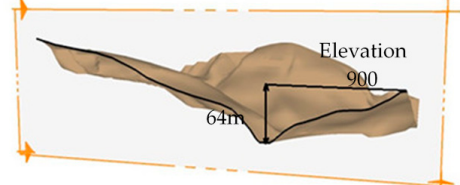

(b)

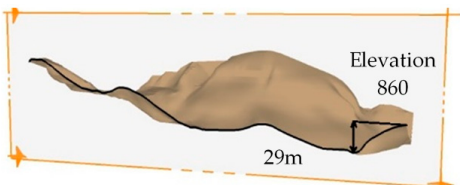

(c)

Figure 6. Sections along the strike of the coal face. (a) Upper part (section A-A); (b) Middle part (section B-B); (c) Lower part (section C-C).

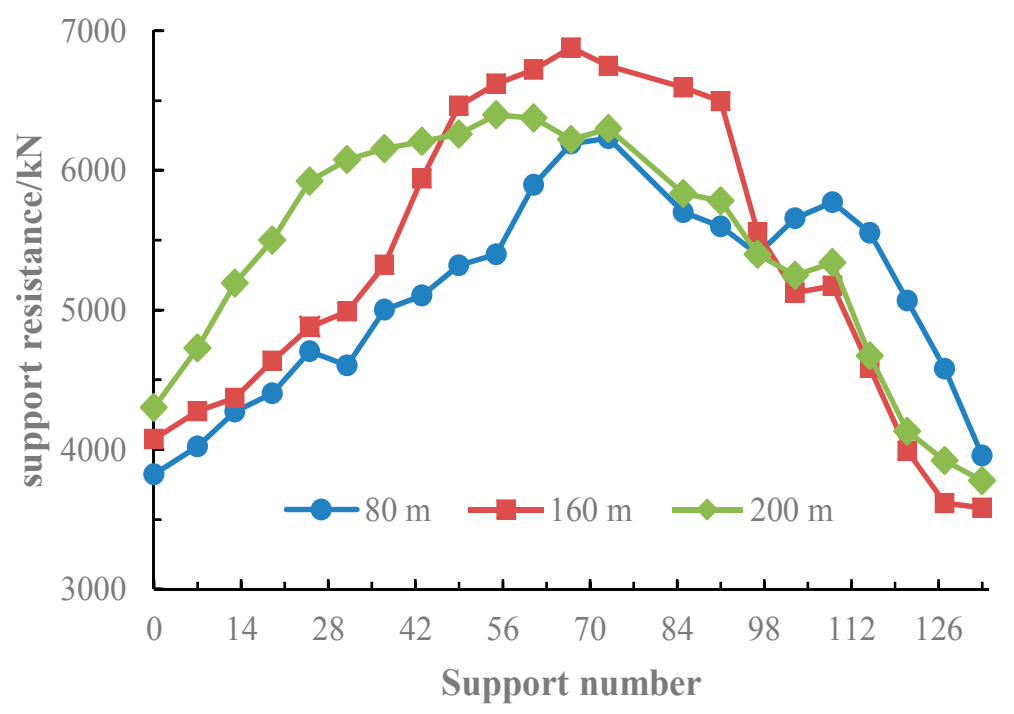

Figure 7. Distribution of support resistance at the coal face.

Table 2. Gully parameters and support resistance along the coal face's strike.

\begin{tabular}{cccc}
\hline Parameter & $\begin{array}{c}\text { Upper Supports } \\
(\mathbf{1 9 \# , ~ 2 5 \# , ~ 3 1 \# ) ~}\end{array}$ & $\begin{array}{c}\text { Middle Supports } \\
(\mathbf{6 1 \# , ~ 6 7 \# , ~ 7 3 \# ) ~}\end{array}$ & $\begin{array}{c}\text { Lower Supports } \\
(\mathbf{1 0 3 \# , ~ 1 0 9 \# , ~ 1 1 5 \# ) ~}\end{array}$ \\
\hline$\alpha\left(^{\circ}\right)$ & 27 & 41 & 43 \\
$h_{0}(\mathrm{~m})$ & 95 & 60 & 29 \\
$H(\mathrm{~m})$ & 305 & 275 & 235 \\
$k$ & 0.311 & 0.218 & 0.123 \\
$R_{\max }(\mathrm{kN})$ & 7560 & 7416 & 7218 \\
$K_{\mathrm{R}}$ & 1.07 & 1.05 & 1.02 \\
\hline
\end{tabular}


As can be seen in Figure 7, for the lower supports, the average support resistance values recorded at $C$ were higher than those at points $A$ and $B$. For comparison, the average support resistance values of the middle and upper supports were higher at points B and A than those at point C. Moreover, the average support resistance values of the lower supports at point B were roughly the same as those at point $A$.

Table 2 shows that the cutting coefficient $k$ of the gully over the upper part of the coal face was higher than 0.3 , and the slope angle $\alpha$ exceeded $15^{\circ}$. The $R_{\max }$ of the upper supports was $7560 \mathrm{kN}$, which is a $7 \%$ increase over that measured at a normal burial depth. This indicates that the gully on the surface exerted some influence on support resistance. The $k$ value of the gully over the face's middle part was about 0.2 , and the corresponding $\alpha$ was relatively large, at $41^{\circ}$. The $R_{\max }$ of the middle supports was $7416 \mathrm{kN}, 5 \%$ greater than that observed at a normal burial depth, which implies that the surface gully had a small influence on support resistance. The $\alpha$ of the gully over the lower part was $43^{\circ}$, and the corresponding $k$ was only around 0.1 . The $R_{\max }$ of the lower supports was $7560 \mathrm{kN}$, which is only $2 \%$ higher than that observed at a normal burial depth, suggesting that the support resistance was nearly unaffected by the surface gully.

\section{Distribution of Support Resistance along the Dip Direction of the Coal Face}

The distribution of support resistance along the coal face's dip direction was analyzed based on the four vertical sections that were parallel to the open-off cut; the corresponding ranges of distance from the coal face to the open-off cut were 150-170 m, 220-240 m, 800-830 m, and 1010-1040 m. Figure 8 consists of schematics of the four sections.

Table 3 compares the parameters of the gully slopes within the four sections and the corresponding support resistance values.

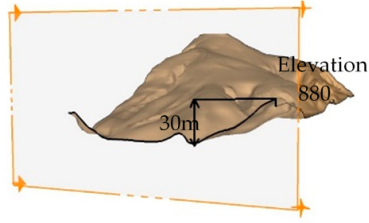

(a)

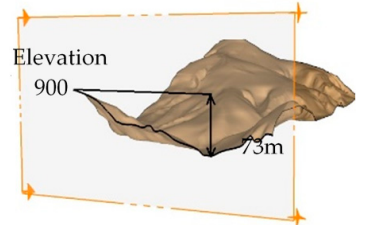

(b)

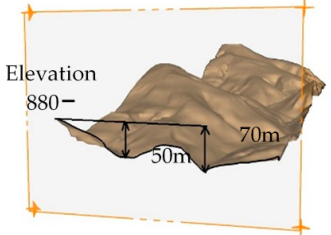

(c)

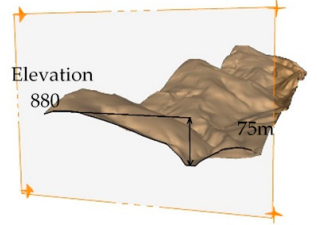

(d)

Figure 8. Sections along the dip direction of the coal face. (a) Section I-I (150-170 m); (b) Section II-II (220-240 m); (c) Section III-III (800-830 m); (d) Section IV-IV (1010-1040 m).

Table 3. Gully parameters and support resistance along the coal face's dip direction.

\begin{tabular}{cccccc}
\hline \multirow{2}{*}{ Parameter } & \multirow{2}{*}{ Section I-I } & \multirow{2}{*}{ Section II-II } & $\begin{array}{c}\text { Section III-III } \\
(\mathbf{1})\end{array}$ & $\begin{array}{c}\text { Section III-III } \\
\text { (2) }\end{array}$ & \multirow{2}{*}{ Section IV-IV } \\
\hline$\alpha\left({ }^{\circ}\right)$ & 32 & 22 & 45 & 51 & 41 \\
$h_{0}(\mathrm{~m})$ & 30 & 73 & 50 & 20 & 75 \\
$H(\mathrm{~m})$ & 250 & 280 & 250 & 210 & 250 \\
$k$ & 0.120 & 0.261 & 0.200 & 0.095 & 0.300 \\
$R_{\max }(\mathrm{kN})$ & 6804 & 7358 & 7325 & 6481 & 7406 \\
$K_{\mathrm{R}}$ & 1.01 & 1.07 & 1.04 & 1.00 & 1.09 \\
\hline
\end{tabular}

Along the dip direction of the coal face, the supports under the gully bottoms exhibited the most significant changes in support resistance. As can be seen in Figure 8 and Table 3, the gully cut through by section I-I was close to supports \#109 through \#133 in the lower part of the coal face; its $k$ and $\alpha$ values were 0.12 and $32^{\circ}$, respectively. The $R_{\max }$ of these supports was $6804 \mathrm{kN}$, an insignificant difference from that measured at a normal burial depth. The gully cut through by section II-II was above supports \#103 through \#115; its $k$ and $\alpha$ values were 0.26 and $22^{\circ}$, respectively. The corresponding $R_{\max }$ was $7358 \mathrm{kN}$, a $7 \%$ increase over that at a normal burial depth. The first gully cut through by section III-III was over supports \#55 through \#73; its $k$ and $\alpha$ values were 0.2 and $45^{\circ}$, 
respectively. The corresponding $R_{\max }$ was $7325 \mathrm{kN}$, which is only a $4 \%$ increase over that recorded at a normal burial depth. The second gully that section III-III passed through was close to supports \#97 through \#115; its $k$ value was low at 0.095 , and the $\alpha$ value was $20^{\circ}$. The $R_{\max }$ of these supports, at $6481 \mathrm{kN}$, is very close to that measured at a normal burial depth. The gully cut through by section IV-IV was in the surface region covering supports \#103 through \#121; its $k$ and $\alpha$ values were 0.3 and $41^{\circ}$, respectively. The corresponding $R_{\max }$ was $7406 \mathrm{kN}$, which represents a significant increase of about $9 \%$ compared to that at a normal burial depth.

\section{Characteristics of Influence of Gullies on Support Resistance}

The results described above suggest that the presence of gullies on the loess-covered surface led to increases in support resistance at the FMTCC face in this thick coal seam. Among the different parameters, the cutting coefficient of gully, $k$, was the key factor influencing support resistance; the higher the $k$ value, the greater the increase in support resistance. By comparison, slope angle $\alpha$ had a relatively small influence on support resistance. For gullies that had roughly the same $k$ values, those with a greater $\alpha$ caused greater increases in support resistance. Table 4 shows the relationship between $k$ and increase in support resistance.

Table 4. Relationship between $k$ and support resistance increase.

\begin{tabular}{ccccc}
\hline$k$ & $>0.26$ & $0.20 \sim 0.26$ & $0.10 \sim 0.20$ & $<0.10$ \\
\hline $\begin{array}{c}\text { Resistance increase } \\
\text { from the average value }\end{array}$ & $>7 \%$ & $4 \sim 5 \%$ & $1 \sim 2 \%$ & No obvious change \\
\hline
\end{tabular}

The characteristics of the surface gullies' influence on the support resistance at the FMTCC in the loess-covered Wangjialing coal mine were similar to those observed at a fully-mechanized mining face in a shallow coal seam. Compared to some surface gullies above the fully-mechanized mining face, the surface gullies in this study led to a more intense rock pressure response at the FMTCC face. The increases in support resistance associated with $k$ values of about 0.26 in this study were nearly equal to those associated with a $k$ of 0.5 in the shallow mine.

Compared to the shallow coal seam, the greater burial depths of the coal seam in the Wangjialing coal mine (200-300 m) reduced the gully slopes' susceptibility to the influence of rock pressure and lowered the gullies' degree of influence on support resistance. Most of the gullies above the FMTCC face had $k$ values of less than 0.26 , and the increases in support resistance were tiny overall, with most below $5 \%$.

\section{Evolution Mechanism of Strata Behavior}

The coal faces in the thick coal seam of the Wangjialing coal mine and the shallow seam mentioned above were compared in terms of overburden movement and forces acting on strata to reveal the evolution mechanism of strata behavior at coal faces under gullies.

Table 5 shows the structures of the overburden and forces on the roof after mining under gullies in different conditions. The shallow coal seam was under a bedrock gully slope. In this table, $G$ is the force of gravity acting upon a polygonal rock block, $T$ denotes the horizontal force on this block, $q$ is the load imposed by the strata above, $R$ is the upward support force applied by underlying strata, and $F$ represents the upward force on a rock block exerted by the adjacent rock blocks that were articulated with it.

It is clear from Table 5a that during the mining of the shallow seam under the gully, the lower overburden broke rapidly under the load of the strata above due to the absence of key strata. Fractures that were roughly parallel and dipped towards the gully bottom developed in the slope body; they divided the slope body into several polygonal rock blocks. These polygonal rock blocks constituted a special articulated structure and tended to rotate towards the gully bottom. In the Wangjialing coal 
mine (Table 5b), the key strata (thick and hard strata) allowed the overburden to form a voussoir beam, a relatively stable structure in the traditional sense, and the strata behavior characteristics were similar to those observed under normal conditions. When the surface gully above this deep seam was similar to that above the shallow seam, the fractures that occurred in the loess-covered slope body resembled those in the bedrock slope body.

Table 5. Overburden structure after mining under gullies in different conditions, and mechanical analysis. FMTCC stands for fully-mechanized top coal caving.

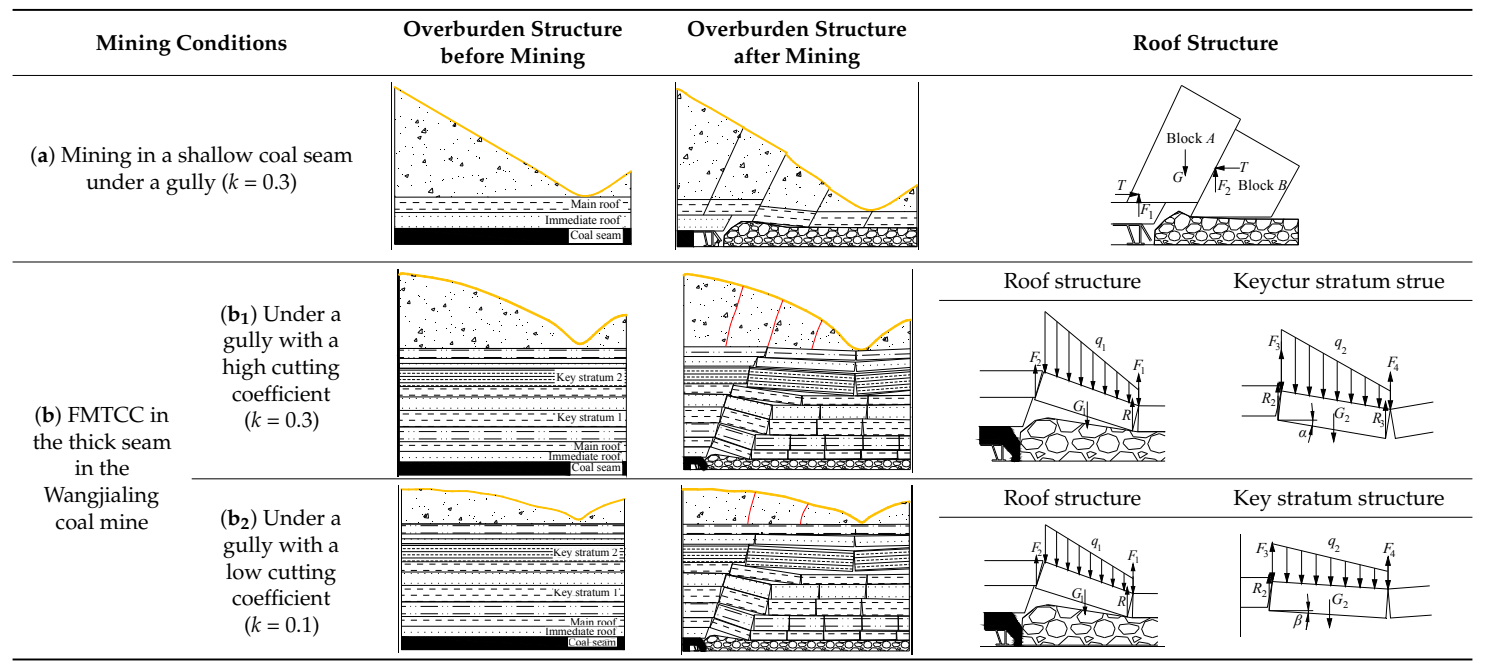

During the mining of the shallow coal seam, the articulated structure that formed from the broken strata easily slid and destabilized, and the load from the caved rock was quickly transferred to the face supports. As a result, the supports were subjected to a sudden rise in pressure, resulting in sharp increases in support resistance. In contrast, in the Wangjialing coal mine, the key strata and other thick, hard strata in the overburden formed a stable load-bearing structure. The articulation between the rock blocks in this structure, together with the support provided by the underlying strata, held up the broken strata above. As the load of upper strata was partly carried by the articulated structure, its magnitude gradually decreased until it was transferred to the face supports. As a result, the pressure on the face supports was relatively low. Moreover, this structure also helped reduce the non-uniformity of load distribution resulting from the surface unevenness. Under a gully with a smaller cutting coefficient (Table $5 b_{2}$ ), the articulated structure was more apparent, and the load on the face supports was more uniform; thus, variations in support resistance were less significant. Additionally, because the breakage of key strata lagged behind (i.e., when the key strata broke, the coal face was far in front of the location of the breakage), the load fluctuation it caused had little impact on the face supports and, thus, the resulting variations in support resistance were not significant.

\section{Conclusions}

The support resistance values measured at the FMTCC face under gullies in the Wangjialing coal mine fell largely within the range of 4500 to $7500 \mathrm{kN}$. They were unevenly distributed along the dip direction of the face; that is, the values from the middle part of the face were higher than those from the upper and lower parts overall.

With the exception of the 7-9\% increases associated with gullies with large cutting coefficients, the increases in support resistance during mining under gullies were generally less than 5\%, suggesting that the surface gullies had little influence on the strata behavior at the FMTCC face.

Because of the increased number of hard and thick strata in the overburden, the more uniform distribution of load, and the lag in the key strata's breakage, the support resistance variations caused 
by gullies in the Wangjialing coal mine were relatively small compared to those observed in the shallow mine.

Acknowledgments: We acknowledge the financial support for this work, provided by the National Natural Science Foundation of China (Grant No. 51474206, No. 51404254, No. 51264035), National Basic Research Program of China (973 Program-No. 2015CB162500), the Fundamental Research Funds for the Central Universities (2014QNA49), Jiangsu basic research program (Natural Science Foundation-No. BK20150051), the Project Funded by the Priority Academic Program Development of Jiangsu Higher Education Institutions (PAPD), C Class Sponsored Project of Jiangsu Province Six Talent Peaks (GDZB-052), and sponsored by Qing Lan Project.

Author Contributions: All the authors contributed to publishing this paper. Xu-feng Wang prepared and edited the manuscript. Yang Wang and Chengguo Zhang participated in the data processing during the research process. Dong-sheng Zhang revised and reviewed the manuscript. Hong-zhi Wang and Dongdong Qin partially participated in the literature research. Yang Zhang was responsible for pictures drawing.

Conflicts of Interest: The authors declare no conflict of interest.

\section{Abbreviations}

$\begin{array}{ll}\text { FMTCC } & \text { Fully-Mechanized Top Coal Caving } \\ \text { FW } & \text { First Weighting } \\ \text { PW } & \text { Periodic Weighting } \\ \text { SOS } & \text { Seismological Observation System }\end{array}$

\section{References}

1. Zhang, N.B.; Liu, C.Y.; Yang, P.J. Flow of top coal and roof rock and loss of top coal in fully mechanized top coal caving mining of extra thick coal seams. Arab. J. Geosci. 2016, 9, 465. [CrossRef]

2. Si, G.; Jamnikar, S.; Lazar, J.; Shi, J.Q.; Durucan, S.; Korre, A.; Zavšek, S. Monitoring and modelling of gas dynamics in multi-level longwall top coal caving of ultra-thick coal seams, part I: Borehole measurements and a conceptual model for gas emission zones. Int. J. Coal Geol. 2015, 144, 98-110. [CrossRef]

3. Unver, B.; Yasitli, N. Modelling of strata movement with a special reference to caving mechanism in thick seam coal mining. Int. J. Coal Geol. 2006, 66, 227-252. [CrossRef]

4. Vakili, A.; Hebblewhite, B.K. A new cavability assessment criterion for Longwall Top Coal Caving. Int. J. Rock Mech. Min. Sci. 2010, 47, 1317-1329. [CrossRef]

5. Xie, Y.S.; Zhao, Y.S. Numerical simulation of the top coal caving process using the discrete element method. Int. J. Rock Mech. Min. Sci. 2009, 46, 983-991. [CrossRef]

6. Wang, J.C.; Yang, S.L.; Li, Y.; Wei, L.K.; Liu, H.H. Caving mechanisms of loose top-coal in longwall top-coal caving mining method. Int. J. Rock Mech. Min. Sci. 2014, 71, 160-170. [CrossRef]

7. Wang, J.C.; Zhang, J.W.; Li, Z.L. A new research system for caving mechanism analysis and its application to sublevel top-coal caving mining. Int. J. Rock Mech. Min. Sci. 2016, 88, 273-285. [CrossRef]

8. Xie, G.X.; Chang, J.C.; Yang, K. Investigation on displacement field characteristics of tunnels surrounding rock and coal seam at FMTC face. J. Coal Sci. Eng. (China) 2006, 12, 1-5.

9. Xie, G.X.; Chang, J.C.; Yang, K. Investigations into stress shell characteristics of surrounding rock in fully mechanized top-coal caving face. Int. J. Rock Mech. Min. Sci. 2009, 46, 172-181. [CrossRef]

10. Li, L.; Liu, Z.G.; Chen, P.P.; Liu, G. Study on fully-mechanized top coal caving mining under water body with shallow overburden and thin bedrock. Adv. Mater. Res. 2013, 734-737, 644-649. [CrossRef]

11. Zhu, Y.J.; Peng, G. Similar material simulation research on movement law of roof over-lying strata in stope of fully mechanized caving face with large mining height. J. Coal Sci. Eng. 2010, 16, 6-10. [CrossRef]

12. Liu, J.; Chen, S.L.; Wang, H.J.; Li, Y.C.; Geng, X.W. The migration law of overlay rock and coal in deeply inclined coal seam with fully mechanized top coal caving. J. Environ. Biol. 2015, 36, 821-827. [PubMed]

13. Yun, D.F.; Liu, Z.; Cheng, W.D.; Fan, Z.D.; Wang, D.F.; Zhang, Y.H. Monitoring strata behavior due to multi-slicing top coal caving longwall mining in steeply dipping extra thick coal seam. Int. J. Min. Sci. Technol. 2017, 27, 179-184. [CrossRef]

14. Yu, B. Behaviors of overlying strata in extra-thick coal seams using top-coal caving method. J. Rock Mech. Geotech. Eng. 2016, 8, 238-247. [CrossRef] 
15. Wang, J.H.; Yu, B.; Kang, H.P.; Wang, G.F.; Mao, D.B.; Liang, Y.T.; Jiang, P.F. Key technologies and equipment for a fully mechanized top-coal caving operation with a large mining height at ultra-thick coal seams. Int. J. Coal Sci. Technol. 2015, 2, 97-161. [CrossRef]

16. Chen, X.H.; Li, W.Q.; Yan, X.Y. Analysis on rock burst danger when fully-mechanized caving coal face passed fault with deep mining. Saf. Sci. 2012, 5, 645-648. [CrossRef]

17. Alehossein, H.; Poulsen, B.A. Stress analysis of longwall top coal caving. Int. J. Rock Mech. Min. Sci. 2010, 47, 30-41. [CrossRef]

18. Shen, J.; Meng, D.; Wei, L. Study on the structural system of roof in fully mechanized top coal caving. Appl. Mech. Mater. 2011, 90-93, 2041-2044. [CrossRef]

19. He, F.L.; Wang, X.M.; Zhang, D.Q.; He, S.S. Study on parameters of support for control of roof fall and rib spalling in large fully mechanized top coal caving end face. Adv. Mater. Res. 2013, 616-618, 421-425. [CrossRef]

20. Du, F.; Bai, H.B. Mechanical model for immediate roof structure of thin bedrock in fully-mechanized sublevel caving face. Electron. J. Geotech. Eng. 2012, 17, 3075-3088.

21. Wang, X.F.; Zhang, D.S.; Zhang, C.G.; Fan, G.W. Mechanism of mining-induced slope movement for gullies overlaying shallow coal seams. J. Mt. Sci. 2013, 10, 388-397. [CrossRef]

22. Wang, X.F.; Zhang, D.S.; Fan, G.W.; Zhang, C.G. Underground pressure characteristics analysis in back-gully mining of shallow coal seam under a bedrock gully slope. Min. Sci. Technol. 2011, 21, 23-27.

23. Wang, X.F.; Zhang, D.S.; Xu, M.T.; Fan, G.W.; Yang, Z.H.; Qin, D.D. Roof instability mechanism of longwall coalface for sandy soil gullies overlaying shallow seams. Disaster Adv. 2013, s6, 260-267.

24. Jia, J.L.; Zhang, D.S.; Cao, L.W.; Wang, X.F.; Ma, L.Q. Main roof fracture mechanism of mining-along-gully in thick loess layer area. J. Mines Met. Fuels 2013, 61, 324-331.

25. Wang, H.Z.; Zhang, D.S.; Wang, X.F.; Zhang, W. Visual exploration of the spatiotemporal evolution law of overburden failure and mining-induced fractures: A case study of the Wangjialing coal mine in China. Minerals 2017, 7, 35. [CrossRef]

26. Zhang, Z.Q.; Xu, J.L.; Zhu, W.B.; Shan, Z.J. Simulation research on the influence of eroded primary key strata on dynamic strata pressure of shallow coal seams in gully terrain. Int. J. Min. Sci. Technol. 2012, 22, 51-55. [CrossRef]

(C) 2017 by the authors. Licensee MDPI, Basel, Switzerland. This article is an open access article distributed under the terms and conditions of the Creative Commons Attribution (CC BY) license (http:/ / creativecommons.org/licenses/by/4.0/). 